This item was submitted to Loughborough's Research Repository by the author.

Items in Figshare are protected by copyright, with all rights reserved, unless otherwise indicated.

\title{
Athlete, anthropologist and advocate: moving towards a lifeworld where difference is celebrated
}

PLEASE CITE THE PUBLISHED VERSION

https://doi.org/10.1080/17430437.2016.1273628

\section{PUBLISHER}

(c) Taylor \& Francis

\section{VERSION}

AM (Accepted Manuscript)

\section{PUBLISHER STATEMENT}

This work is made available according to the conditions of the Creative Commons Attribution-NonCommercialNoDerivatives 4.0 International (CC BY-NC-ND 4.0) licence. Full details of this licence are available at: https://creativecommons.org/licenses/by-nc-nd/4.0/

\section{LICENCE}

CC BY-NC-ND 4.0

\section{REPOSITORY RECORD}

Howe, David. 2017. "Athlete, Anthropologist and Advocate: Moving Towards a Lifeworld Where Difference Is Celebrated”. Loughborough University. https://hdl.handle.net/2134/32455. 


\section{Athlete, Anthropologist and Advocate: moving toward a lifeworld where difference is celebrated}

\section{By P. David Howe}

This paper is a call to scholars working within the sport studies researching the Paralympic communitas, to embrace the use of reflexive ethnography. The nature of ethnographic research places the social scientist in a privileged position. On the one hand there is a need to transfer knowledge to the academic community but on the other this should not occur as a result of the exploitation of the people under investigation. Using a reflexive historical ethnographic vignette as a starting point this paper highlights how our past embodied interactions, with the lifeworld can impact upon the shape and colour of the lens in which we view it. Ultimately this paper argues that by adopting a phenomenological stance we can gain a better understanding of the degree to our body as a vessel for data collection can enhance our understand of the cultural milieu surrounding the Paralympic movement.

Key words: impairment, phenomenology, reflexive ethnography, Paralympic sport

When we attend to our experiences not as intangible minds but as, speaking bodies, we begin to sense that we are heard, even listened to, by the numerous other bodies that surround us. Our sensing bodies respond to the eloquence of certain buildings and boulders, to the articulate motions of dragonflies. We find ourselves alive in a listening, speaking world (Abram, 1996: 86).

This quote by Abram reminds us that being in the world is full of sensuous experience. The purpose of this current paper is to highlight how sensuous ethnographic accounts can help shape a research agenda as well as our interpretation of the lifeworld. The vignette below provides an example of what a narrative turn celebrated by Rorty who felt that objectivity was a product of social agreement which led to "descriptions of the world which are useful for purposes of prediction and controlling what happens” (Rorty, 1989: 4). As a historical narrative passed down to me by my parents with my own degree of creative fiction (Sparkes, 2002) added the vignette is used as a vehicle to discuss the broader issue of how key moments in our lives can be instrumental in shaping who we become. Using such methods in an ethnographic tool kit (Howe, 2009) and the presence of an ethnographer, who we must remember is a sensuous vessel for the collection and dissemination of data in the cultural milieu surrounding him or her, might go some way to increasing our understanding of the lifeworld.

As we go through life we are often asking ourselves - what if I had chosen a different path or a different path had been chosen for me. The 'what if' question was entertainingly enacted in the 1998 British film Sliding Doors by a fictional character portrayed by Gwyneth Paltrow who misses the tube (subway train) in central London. The film chronicles how the simple act of changing the course of one's life even in the most simple and innocent manner can have long-term consequences. We are all confronted with the preverbal 'fork-in-the-road' from 
time to time and what follows is a brief historical ethnographic tale in which I am one of the central characters ...

I am a child of the mid 1960's born to educated parents in a small town in Southern Ontario CANADA. The parental joy that I was normal - with the requisite number of fingers and toes - was eventually overcome by anxiety and concern as I failed an early normality milestone. Books on childhood development suggest that children should begin walking roughly between 9 and 18 months and I had failed to achieve this target. Generally around fifty percent of babies usually walk by one year of age. Walking is a matter of coordinating three factors: muscle strength, balance, and temperament, and the latter seems to influence the age of walking the most. Because to the untrained eyes of my parents there was nothing 'wrong' with me and they were concerned and perhaps a little anxious that I was 'slow' to develop and worried whether my inability to walk was to do with my temperament - wondering if as their first child they had 'created' an abnormal tendency towards dependents as those children who develop a more independent streak were considered at the time to be more likely to engage in walking to explore the far reaches of their world - largely the confides of their home or other environment that the parents felt safe letting them go 'free'!

Concerned with my lack of pedestrian development my parents booked me in for series of examination at Toronto's Sick Children's Hospital. The name of this institution still sends shiver down my spine today in large part because of how so called 'medical expert' dealt with my parents' concerns. It should be remembered however that the medical diagnosis and opinion expressed to my parents are over forty years old and one has to assume a more 'enlightened' approach would be adopted today.

My father took the day off work and drove my mother, my 'new born' brother and myself the 100 miles to the hospital where I was put through a battery of tests. These tests were not explained, to my parents and at their conclusion I was exhibited, in my 'birthday suit' no less, to a large group of medically trained professional some of whom were in the middle of their medical training. A number of young children one after another were placed on the stage and diagnosed by this collection of experts. When my turn arrived I was a typical happy, jolly 23 month old delighted, if rather cold, to be the centre of attention. What my parents were told was a Sliding Doors moment both for them and me! 
The diagnosis now is self-evident - Cerebral Palsy - hemiplegia to be exact that would impact upon my physical development. Cognitive tests that were done came back as normal much to the relief of my mother who had grave fears of intellectual impairment. My father was more concerned with the physical impact on his first born not being able to engage in sport. My father was an elite track and field athletics coach who was completely devoted to the sport and to him it was paramount that I be able to enjoy the feeling of running. This in the eyes of the medical experts present this would NEVER happen. The treatment required to get me walking was a relatively simple operation - a fusion of the bones in my ankle. To my father this was hugely problematic. In an agitated state he question medical authority and simple stated

'If you fuse his ankle, David will not be able to run!?'

The response from the doctor in charge was simple.

'Your son will not be able to run regardless of whether he has the operation or not but he will be able to walk in time - otherwise his life is likely to be more sedentary than that of normal children his age. He will not have the balance to ride a bike for example.'

This statement and the spectre of raising a handicapped child - hit my parents hard. They could see an anvil being tied around their necks in much the same way as the Warner Brothers Looney Tunes cartoon character the Wile E. Coyote, when he gets dragged over a precipice. My mother was traumatised - what had she done to deserve a handicapped child? My father on the other hand was furious. By the time he got the family bundled back into the car and finished consoling my mother he was clear in his mind that my ankle WOULD NOT be fused. A couple of weeks later after signing his life away in 'blood' I was fitted for a small below the knee brace and moments after first wearing it I began to walk.

The vignette is a creative historical fiction (see Sparkes, 2002). It is rather selfevident that as the young subject of the narrative I was not in a position to make my own observations of events, but had things been different, I might not have been the author of a paper such as the one you are reading.

Debate surrounding writing culture of which this vignette is a product has drawn attention to the shortcomings of ethnographic methods (Clifford and Marcus 1986; James, Hockey and Dawson 1997; Coffey 1999; Davies 1999; Sparkes 2002). These debates 
alerted anthropologists to the need to pay closer attention to the epistemological grounds of their representations and, furthermore, has made them consider the practical import of that process of reflection, both for the anthropological endeavour and for those who are the subjects of any anthropological enquiry (James, Hockey and Dawson 1997:3)

In a sense then the postmodern turn in anthropology (Marcus and Fischer 1986; Clifford and Marcus 1986) and in the social sciences more generally (Coffey 1999) has led to a discussion about the validity of ethnographic methods. Many of the readers of this vignette may question its value but the bottom line in many of these debates has simply been that 'objectivity is impossible' and 'subjectivity undesirable' (Peacock 1986:87). Doing ethnography, these debates suggest, is not as simply as going on holiday and writing a diary because the act of participant observation is trapped in a cultural environment that is continually being transformed not just by the peoples being researched but also by the researcher (Clifford 1986). The product of the ethnographer, the literary output, whether fieldnotes, draft or published texts from the research, are steeped in a distinctive cultural heritage. As a result, '[e]thnographic truths are thus inherently partial committed and incomplete (Clifford 1986: 7).

Given the complexity of ethnography, it is obviously difficult to generalize globally based on single ethnographic accounts. It is wrong to synthesize merely substantive or 'factual' findings of ethnographic investigations, for each ethnography is more than a report, a mere shortcut for being there. Each is an interpretation, a synthesis of questions, theories, and attitudes that guide the interpreter as well as facts reported. At the same time, the empirical or inductive approach characteristic of social scientific generalisation is a necessary antidote to purely deductive or introspective efforts at reflecting on human nature.

To a point these debates have validity in that attempting to establish a concrete truth as a goal within the social sciences is a 'fools errand'. I am acutely aware of this debate. In recent years ethnography has become a popular approach to the social investigation of sporting cultures. There is however some confusion as to what constitutes the use of ethnographic methods within the multi-disciplinary field of sports studies. The term ethnography is used in two distinct ways within social research: that of ethnographic research and that of an ethnographic monograph. It does not mean simply 'qualitative'. As a noun, it means a description of a culture, or a piece of a culture. As a verb (doing ethnography), it means the collection of data that describe a culture. It is simply a methodology of social scientific research. Ethnography is characterized by the first-hand study of a small community or ethnic group. This form of study combines varying degrees of descriptive and analytical elements, but of key importance in conventional ethnographies is that they focus on one specific culture or society and consider theoretical or comparative generalizations from the standpoint of the ethnographic example. 
As I write this paper my ethnographic engagement with the cultural politics of the Paralympic movement from the perspective of both an insider and an outsider (see Howe, 2008) has gone some way to enhancing our understanding of the relationship between impaired bodies and the practice of sport in a world where difference is seldom celebrated.

The vignette above which contains some information previously mention in publication (see Howe, 2008) is a preface to anything I have written about myself as an ethnographer. The love and commitment of both my parents and my father's instance that movement in the pursuit of sporting dreams was important still shape the manner in which I view the world today. For my research related to the practice of Paralympic sport specifically and the impact and influence that it can potentially have upon wider society the fact that my father would not allow my body to undergo recommended medical intervention is of great significance. My insights into the workings of the Paralympic communitas would not be the same if my ankle had been fused. I may have still been an anthropologist, but my sporting experience certainly would have been very different. I may not, for example, have been able to proudly call myself a Paralympian. As such I now wish to turn my attention to centrality of phenomenology, the sensuous body in the practise of ethnographic fieldwork.

\section{Phenomenological Ethnography}

The use of phenomenology has been central to good ethnography for a long time (Davies, 1997) since self-changes and transforms beside (and sometimes along with) the social environment under investigation. By its very nature then the act of constructing an ethnographic account is autobiographical. 'Fieldwork is personal, emotional and identity work.' (Coffey, 1999: 1). Yet it is not an exact reflection of the lived experience of the author since

The writing and reading of ethnography are overdetermined by forces ultimately beyond the control of either an author or an interpretive community. These contingencies - of language, rhetoric, power and history - must now be openly confronted in the process of writing (Clifford 1986: 25)

As a result, ethnographic researchers are becoming more conscious that phenomenological experience impacts upon the data collected and written. By using reflexive ethnography to tell stories and allowing readers to be the arbiters of meaning understanding can be enhanced (Ellis and Bochner, 2000: Sparkes, 2002). It is now more often than not the world of the ethnographer that is being explored. One of the dangers of this phenomenological position is that the truths discerned by self-examination may be too closely bound to the experience of the researcher 
and the categories of their culture. Yet again, like the vignette in this paper, it is open to interpretation.

My aim here is to encourage what feminists refer to as standpoint epistemology that places the voice of the underrepresented as the centre of research (see Brooks, 2007). Traditionally this approach has focused on including women's voices. Wendell (1996) has shown that this approach has value when centring the voices of impaired individuals. In the vignette that began this paper because of its historical dimension, for example it is my father's voice that is central to the story but it is my retelling of it that gives in political capital. The point is that in my recounting of this family parable I have shaped it to give meaning to my advocacy. There is 'truth' in the manner, tone, and lexicon - the use of the word 'handicap', a product of the 1960s - but now out of fashion in English. Also factual is my father's passion for his particular brand of social justice. In essence the vignette signals the starting point of my sporting career but also my activism.

Using the phenomenological position of 'being in the world' the reflexive ethnographer adopting a standpoint epistemology can piece together disablist thoughts and deeds. In this way 'disability is conceptualized as the social imposition of restrictions of activity on people with impairments' (Thomas, 1999: 123). An ethnographer with impairment is therefore in a unique position to document what could be called disability in action - that is the impact of the impaired body on an otherwise ordinary sporting space and political landscape. Following Thomas (1999) the notion of disability in action is informed by an understanding of disability that is socially relational. That is

The social relational formulation indicates that the term disability expresses an unequal power relationship between those who socially constructed as 'impaired' (the relatively powerless) and those who are identified as 'non-impaired' or 'normal' in society (the relatively powerful). (Thomas, 1999:124)

The act of being someone impaired body in practice community (see Morgan, 1994; Howe and Jones, 2006) that is in part made up of other individuals with impaired bodies - yet the power resides with the 'able' moral majority and my embodiment facilitates the opportunity to collect data on this power dynamic.

The embodied sensuous ethnographer has a role to play in shaping the lifeworld under investigation. It is difficult if not impossible to know how the involvement of the ethnographer shapes the social environment but what is certain is that in more long term or diachronic studies of communities where the researcher is seen to be an adjunct member of the community the influence may be less marked. Today a community is not always the bounded entity that anthropologists engaged with in the past, such as a well-defined group of islanders living in remote regions. Rather communities, such as the Paralympic family, are more emotive than this. Recently Amit has suggested 
The emotive impact of community, the capacity for empathy and affinity, arise not just out of an imagined community, but in the dynamic interaction between that concept and the actual and limited social relations and practices through which it is realized (2002:18)

The nature of communities that are no longer seen as bounded means that most sport ethnography makes it more difficult for the ethnographer to make the distinction between inside and outside of the research field. As such, unbounded communities can facilitate a transformation of the ethnographer's worldview to the point in some cases where they can find it difficult to distinguish the uniqueness of the cultural environment at the heart of the study. In many respects then the act of going native is not ever clear cut but in the context of anthropological literature 'going native' is often seen as a failing on behalf of the ethnographer to position themselves in relation to the data they are investigating - to become an outright participant - more than simply engaging with the experience to the point where you fail to record observation. It is of course very difficult to balance the amount of participation and observation that the ethnographer is engaged in at any one time during the research process. However, the reflexive character of this form of social research implies:

that the orientations of researchers will be shaped by their sociohistorical locations, including the values and interests that these locations confer upon them. What this represents is a rejection of the idea that social research is, or can be, carried out in some autonomous realm that is insulated from the wider society and the particular biography of the researcher, in such a way that its findings can be unaffected by the social processes and personal characteristics (Hammersley and Atkinson 1995:16)

Because of the issues and concerns highlighted above, and the fact that people who are members of the communities that social scientists wish to investigate, are not naive about the 'outsider' and the impact they may have on the social environment they are studying, issues of access are important to consider.

\section{Entering the Paralympic Communitas}

The cerebral palsy that impacts upon the normal function of my body was my ticket to my early involvement with the Paralympic communitas. This entry into the field also coincided with the end of my first year as an undergraduate anthropology student. I should make clear at this point that entry into the 'field' is neither clear cut or simple because no longer are the sites of ethnographic research demarcated distinctive environments (Marcus and Fischer 1986). Traditionally the understanding has been that an ethnographer is immersed in the field, establishes relationships with relevant gatekeepers and simply extracts the data that provide a detailed cultural understanding. However, '[t]he notion of immersion implies that 
the 'field' which ethnographers enter exists as an independently bounded set of relationships and activities which is autonomous of the fieldwork through which it is discovered (Amit 2000: 6)'. Access to the field in many cases needs to be continually renegotiated. Since the location of field sites is fluid it makes access more problematic than traditional community-based ethnography. In a sense then there has been a shift away from the place or location as the focal point for the development of culture. As Amit suggests,

The shift away from locality as the boundary and site for cultural production has allowed anthropologists to take more cognizance of migrants and travellers whose social networks and frames of reference are likely to be dispersed and multilocale rather than conveniently fixed in one place (2000: 13)

In light of this it seems that it is appropriate to explore the cultural politics of the Paralympic movement where ethnographic data have been collected on various continents in a diachronic fashion over three decades. Following Appadurai

What a new style of ethnography can do is to capture the impact of deterritorialization on the imaginative resources of lived, local experiences. Put another way, the task for ethnography now becomes the unravelling of a conundrum: what is the nature of locality, as lived experience, in a globalizing, deterritorialized world? (1991: 196)

Those adopting ethnography as a research tool therefore became more sensitive to their own identities and the impact of this on their research findings. De Garis (1999) has gone so far as to suggest that the ethnography of sport should be turned into a sensuous ethnography where the participant ethnographer records all aspects of the sensuous experience of fieldwork. This new enlightened approach to ethnographic representation coupled with other methodologies that are more commonly employed in social investigations of the sport (interview and survey) leads to a more complete understanding of the sporting world.

\section{Discussion}

Being aware of my body as I am and the fact that its difference, had it not been for my parents, would have led to my potential exclusion from running making this an apocryphal tale. Running is a physical activity I have invested a great deal of physical and emotional energy into and for those thinking about sporting opportunities for marginal populations they need to be mindful how seemingly simple straight forward decisions, made by experts, can impact upon someone life. I was lucky. My body has certainly shaped the discourse that I use in my research and has made me passionate about celebration of difference. As such my body is instrumental as a tool for ethnographic research. In his classic ethnography of impairment Murphy (1987) highlights how his body both becomes an object of attention for him as well as others. 'The body no longer can be taken for granted, 
implicit and axiomatic, for it has become a problem. It no longer is the subject of unconscious assumption, but the object of conscious thought' (1987: 12). This is the case for both the impaired individual as well as the society that needs to deal with the 'problem' created by the abnormal body. In other words, the difficulties in managing impaired bodies can put a strain on social systems which for some can be seen as problematic. On the other hand, the development of a disability business (see Albrecht, 1992) where medical professionals and pseudo professionals work to 'better' the lives of the impaired is designed in part to control and/or eliminate the problem of physical difference. Of course, the involvement of disability industry workers does not and cannot eliminate physical difference but establishes it as a constant that the 'perfect' can be happy about not achieving.

The disability industry of which the Paralympic communitas is now an integral part creates an environment that perpetuates the differences between impaired individuals and the able moral majority. In a sense those people working in the disability industry are catalysts for disablism. Disablism is, according to Miller et al (2004: 9), 'discriminatory, oppressive or abusive behaviour arising from the belief that disabled people are inferior to others.' Over the last twenty-five years there have been both national and international legislation passed by governments that has greatly reduced overt disablism. The elimination of overt disablist attitudes makes the lives of impaired people better opening up opportunities for work and leisure pursuits such as sport, although some feel there is a long way to go before equity is achieved. As Deal suggests

Not all forms of prejudice and discriminatory behaviour, however, are blatant and therefore easily identifiable, as subtle forms of prejudice also exist. Therefore, any attempt to tackle prejudice towards disabled people must not only focus on overtly discriminatory behaviour but also recognize subtle forms of prejudice, which can be equally damaging. (2007: 94)

The disablism that confronts me and those like me on a daily basis is not blatant but a subtle form of prejudice. Because of the subtle nature of disablism it often falls under the radar established by legislation designed to improve the lives of impaired people. Disablism is hard to detect and the able majority may be unaware that they are being disablist. Therefore a phenomenological approach to ethnography - an auto-ethnography done by social scientists can be so enlightening. My use of my impaired body as a vehicle for research in the Paralympic communitas will increase our understanding of aversive disablism which can be very difficult to quantify.

Aversive disablists may not be anti-disabled, but rather pro-nondisabled. This theory may hold true for both disabled and nondisabled people, bearing in mind people do not on the whole choose 
to be disabled, but not choosing to be disabled does not mean the person will automatically be anti-disabled (Deal, 2007: 97)

Employing my impaired body 'in the world' and recording this experience in a reflexive ethnographic manner will help to establish a sense of the nuances involved in aversive disablism. But we must be careful. Those individuals who do not identify themselves as a product of disablist attitudes, regardless of the severity of their impairment who feel they have liberal views toward others with impairments may be ambivalent to prejudice. Not everyone who is a social researcher will be willing therefore to engage in an autoethnography of disability in action. A key point here is that I feel the social construction of a definable 'normal body' is problematic. The only thing that should be celebrated as normal is vulnerability. Alasdair MacIntrye (1999) in his landmark work Dependent Rational Animals tells us that a key human universal is vulnerability. If this is the case, and I believe it is, then why is the celebration of difference so difficult? Goffman (1963) has suggested that some people establish an able identity as a way of passing as 'perfect' in part because they feel acknowledging their imperfection, dare I say vulnerability, will evoke strong feelings of altruism and sympathy. This masquerade (Sieber, 2004), or passing as what we are not, can lead to further aversive disablism (Deal, 2007) for those who are 'out' about their frailties whether they are considered impaired or not.

I have not always been comfortable with my impaired body. The vignette that is central to this discussion highlights uncheck authority can change the course of a life and impact upon identity. It has to be said that my identity with a fused ankle would have been different - I do not have the insight to know for certain whether it would have been better or worse. Whether running or doing less specific daily activities I have lived with the fact that my body is different in part because of how others react to it. The simplest of acts like a handshake or running around a local park does not conform to standards of normality often entails a judgement on the part of others. Often these judgements take the form of aversive disablism.

As I have grown to adulthood I have become increasingly concerned with what the able moral majority is doing on behalf of the impaired populations. The Paralympic Movement is part of a disability business, to borrow a phrase from Albrecht (1992) that will likely begin to regulate itself without cause or concern for the people it was designed to serve, as has been the case with so many well intended social movements.

All too often in society we establish concepts like human rights and their associated by-product of legislation, social justice (Rawls 1971) in order to establish a foundation on which to give the underprivileged 'a better lot in life'. To date these interventions have not worked. The United Nations (UN) continues the propaganda that 'the vulnerable matter as articulated through the Vienna Declaration of 1993 (which focuses upon women and other minority voices) and 
the more recent Convention on the Rights of Persons with Disabilities of 2006 but this legislation has done little to enhance people's lives.

\section{Summary}

In a sense my tactics for undertaking this research highlight the 'inextricable relationship between epistemology, politics and practice which the "Writing Culture” debate drew attention to’ (James et al 1997:2). As such an understanding of the fluidity of culture is key and important. We now know that,

'Cultures' do not hold still for their portraits. Attempts to make them do so always involve simplification and exclusion, selection of a temporal focus, the construction of a particular self-other relationship, and the imposition or negotiation of a power relationship (Clifford 1986:10)

The 'writing culture' debate surrounding issues of representation does provide insight to ethnographers. It is important that readers know where the author is coming from. In other words what methodological position I have taken in the field, combined with the autobiographical account of 'where I am coming from' might be taken as a way forward in the field of Paralympic studies or the studies of sporting culture more generally.

Ultimately our daily task, whatever our role in life, is to continually re-evaluate the lifeworld around us so that it continues to make sense. Largely we do this unthinkingly. Our existence and the roles that we play are generally not questioned. It is apposite at this moment in time that those who occupy roles within the Paralympic movement, regardless of how central those might be, examine whether their position enhances the opportunities of athletes with impairments.

I have called for the use of both reflexive ethnography and standpoint epistemology within the Paralympic communitas by social scientists because it is my belief that doing so it will increase our understanding of the continuum of disablism. Overt disablism is easy to spot in both people and buildings but there is a need to draw on a phenomenological ethnographic understanding of our vulnerability in an attempt to understand and hopefully eradicate aversive disablism.

It may not be that simple as

The writing and reading of ethnography are overdetermined by forces ultimately beyond the control of either an author or an interpretive community. These contingencies - of language, 
rhetoric, power and history - must now be openly confronted in the process of writing (Clifford 1986: 25)

Ultimately, this brief paper was designed to make us all question our position with the moral maze that is social research. The vignette at the heart of this paper is designed to illuminate the position from which I explore some of these important questions. We are all confronted with Sliding Door moment in our lives ... and in this instance I cannot help wondering 'What if ... my ankle had been fused?'

\section{References}

Abram, D. (1996) The spell of the sensuous: Perception and language in a morethan-human world. New York: Vintage Books.

Albrecht, G. (1992) The Disability Business - Rehabilitation in America, London: Sage.

Amit, V. (2000) 'Introduction: constructing the field', in Amit, V. (ed.)

Constructing the Field: ethnographic fieldwork in the contemporary world. London: Routledge. p. 1-18.

Amit,V. (2002) 'Reconceptualizing Community', in Amit, V. (ed.) Realizing Community: concepts, social relationships and sentiments. London: Routledge.

Brooks, A. (2007) 'Feminist Standpoint Epistemology' in Hesser-Biber, S.J.N and P.L. Leavy Feminist Research Practic : a primer. London: Sage.

Chick, G. (1998) Leisure and Culture: Issues for an Anthropology of Leisure. In Leisure Sciences. Vol. 20:111-133.

Clifford, J. (1986) 'Introduction: Partial Truths' in Clifford, J. and G. Marcus (eds.) Writing Culture: The Poetics and Politics of Ethnography. Berkeley: University of California Press. p. 1-26

Clifford, J. and G. Marcus (eds.) (1986) Writing Culture: The Poetics and Politics of Ethnography. Berkeley: University of California Press.

Coffey, A. (1999) The Ethnographic Self: fieldwork and the representation of identity. London: Sage.

Davies, C. A. (1997) Reflexive Ethnography: a guide to researching selves and others. London: Routledge.

De Garis, L. (1999) Experiments in Pro Wrestling: Toward a Performative and Sensuous Sport Ethnography. In Sociology of Sport Journal. Vol. 16. 6574.

Deal, M. (2007) 'Aversive disablism: subtle prejudice toward disabled people’, Disability \& Society. Vol. 22 (1): 93-107.

Ellis, C. and Bochner A. (2000) 'Autoethnography, personal narrative, reflexivity: researcher as subject.’ In Denzin, N.K. and Lincoln, Y.S. (eds) Handbook of Qualitative Research. London: Sage pp. 733-768.

Hammersley, M. and Atkinson, P. (1995) Ethnography: principles and practice. (Second Edition). London: Routledge. 
Howe, P.D. and Jones, C. (2006) 'Classification of Disabled Athletes: (Dis)empowering the Paralympic Practice Community' in Sociology of Sport Journal. Vol. 23. 29-46.

Howe, P. D. (2008) The Cultural Politics of the Paralympic Movement: Through the Anthropological Lens. London: Routledge.

Howe, P. D. (2009) 'Reflexive Ethnography, impairment and the pub', Leisure Studies. Vol. 28.(4): 489-496.

James, A., J. Hockey and A. Dawson (1997) Introduction: the road from Santa Fe. In James, A., J. Hockey and A. Dawson After Writing Culture: Epistemology and Praxis in Contemporary Anthropology. London: Routledge. p. 1-15.

Leder, D. (1990) The Absent Body. London: University of Chicago Press.

Marcus, G. and M. Fischer (1996) Anthropology as Cultural Critique: An experimental Moment in Human Sciences. Chicago: University of Chicago Press.

Merleau-Ponty, M. (1962) Phenomenology of Perception. London:Routledge\& Kegan Paul

Miller, P., Parker, S. and Gillinson S. (2004) Disablism: how to tackle the last prejudice. London: Demos.

Murphy, R. F. (1987). The Body Silent. London: Dent.

Nixon, H. L. (2007) 'Constructing Diverse Sports Opportunities for People with Disabilities’, Journal of Sport and Social Issues. Vol. 31 (4) p.417-433.

Oliver, M. (1990) The Politics of Disablement. London: Macmillan.

Peacock, J. L. (1986) The Anthropological Lens: harsh light, soft focus. Cambridge: Cambridge University Press.

Rawls, J. (1971) A Theory of Justice. Harvard University Press.

Shakespeare, T. (2006) Disability Rights and Wrongs. London: Routledge.

Siebers, T. (2004) 'Disability as Masquerade' Literature and Medicine Vol. 23 (1):1-22.

Siebers, T. (2008) Disability Theory. Ann Arbor: University of Michigan Press.

Sparkes, A. C. (2002) Telling Tales in Sport and Physical Activity: a qualitative journey. Leeds: Human Kinetics.

Thomas, C. (1999) Female Forms: Experiencing and understanding disability. Buckingham: Open University Press.

Wendall, S. (1996) The Rejected Body: Feminist Philosophical Reflection on Disability. London: Routledge.

Van Maanen, J. (1988) Tales of the Field: on writing ethnography. London: University of Chicago Press. 